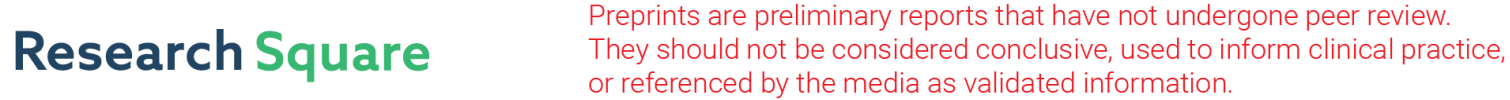 \\ Coupled Structural-Rheological Numerical Analysis of Injection Mold
}

Cedrico Oliveira ( $\square$ cedric.resende.oliveira@gmail.com )

Universidade do Minho - Campus de Azurem https://orcid.org/0000-0002-2708-2822

Nuno Peixinho

Universidade do Minho - Campus de Azurem

José Meireles

Universidade do Minho - Campus de Azurem

\section{Research Article}

Keywords: Moldflow, ANSYS, Injection mold, Structural analysis, Metal fatigue analysis

Posted Date: April 22nd, 2021

DOI: https://doi.org/10.21203/rs.3.rs-382239/v1

License: (1) This work is licensed under a Creative Commons Attribution 4.0 International License.

Read Full License 


\title{
Coupled structural-rheological numerical analysis of injection mold
}

\section{Authors information:}

Cedrico Oliveira; Universidade do Minho - Departamento de Engenharia Mecânica; Guimarães Portugal; cedric.resende.oliveira@gmail.com; ORCID: 0000-0002-2708-2822

Nuno Peixinho; Universidade do Minho - Departamento de Engenharia Mecânica; Guimarães Portugal; peixinho@dem.uminho.pt

José Meireles; Universidade do Minho - Departamento de Engenharia Mecânica; Guimarães - Portugal; meireles@dem.uminho.pt

\begin{abstract}
:
The production of injection molds is an important industry for manufacturing of plastic parts. Considering that time to market reduction is important, it becomes fundamental the use of numerical simulation to reduce design errors. The objective of this work is the presentation of an algorithm for the connection between Moldflow and ANSYS to import loads and then the study of the differences on the approaches studying the tool behavior when considering quasi-static or transient numerical simulation. From this work it was possible to have an overview of where each kind of simulation approach could be used.
\end{abstract}

Keywords:

Moldflow, ANSYS, Injection mold, Structural analysis, Metal fatigue analysis

Declarations:

Founding: This work was supported by MEtRiCs - Mechanical Engineering and Resource Sustainability Center from Universidade do Minho and Grupo Simoldes by providing the needed software's and model to study.

Conflicts of interest: The author Cedrico Oliveira is an employee from Grupo Simoldes and researcher in MEtRiCs as for the other authors they are researchers in MEtRiCs.

Authors' contributions: The author José Meireles was the project administrator and supervisor, the author Nuno Peixinho was responsible for the review and editing of the paper, as for the author Cedrico Oliveira was responsible for the methodology, investigation, application development, conceptualization and writing the original draft.

Availability of data and materials: Some of the data was generated in the Simoldes Group so it can't be shared for the exception of what is presented in the paper, the code for the application is the intellectual property of the author Cedrico Oliveira so it can be explained and presented but the source code can't be shared. The authors are available to discuss the data with any reviewer to explain the procedure and the obtained data.

Consent to participate: Not applicable.

Ethical approval: Not applicable. 


\title{
Coupled structural-rheological numerical analysis of injection mold
}

\author{
Cedrico Oliveira' ${ }^{1,2}$, N. Peixinho ${ }^{1}$, J. Meireles ${ }^{1}$ \\ ${ }^{1}$ MEtRiCs - Mechanical Engineering and Resource Sustainability Center, University of Minho, Guimarães, Portugal \\ 2 cedric.resende.oliveira@gmail.com
}

\section{ART I C L E I N F O}

Keywords:

Moldflow

ANSYS

Injection mold

Structural analysis

Metal fatigue analysis

\begin{abstract}
A B S T R A C T
The production of injection molds is an important industry for manufacturing of plastic parts. Considering that time to market reduction is important, it becomes fundamental the use of numerical simulation to reduce design errors. The objective of this work is the presentation of an algorithm for the connection between Moldflow and ANSYS to import loads and then the study of the differences on the approaches studying the tool behavior when considering quasi-static or transient numerical simulation. From this work it was possible to have an overview of where each kind of simulation approach could be used.
\end{abstract}

\section{Introduction}

An injection mold is a precision tool and one of the most common processes to fabricate thermoplastic parts [1]. Nowadays the use of numerical simulations is getting very common to determine the best filling parameters for plastic parts. Software's are used to understand and anticipate the problems that may occur during the filling, packing and cooling phase, and several works have been made to study improved ways to determine those parameters [2][6]. Such values are very useful to determine the needed forces for the injection machines or to design the extraction of the plastic parts [7] or stresses that are present in the injection mold [8]. There are mechanisms for transferring information between rheology software's such as Moldflow and structural software's such as ANSYS but, always with the objective of studying the behavior of the plastic parts. In this work it will be shown an approach to link the information present on Moldflow into ANSYS so a coupled analysis of the tool can be performed.

To perform the structural analysis there are two approaches for those numerical simulations, i.e., it is possible to conduct a quasistatic analysis or a transient analysis. Equation (1) is the general equation for the transient simulations where is possible to observe how time affects the results.

$$
[M]\{\ddot{u}\}+[C]\{\dot{u}\}+[K]\{u\}=\{F(t)\}
$$

Where $[\mathrm{M}]$ is the mass matrix, $[\mathrm{C}]$ the damping matrix, $[\mathrm{K}]$ the stiffness matrix, $\mathrm{F}$ the force, $\{\mathrm{F}(\mathrm{t})\}$ the load vector, $\ddot{u}$ the nodal acceleration vector, $\dot{u}$ the nodal velocity vector and $\mathrm{u}$ is the nodal displacement vector. For quasi-static simulations $[M]\{\ddot{u}\}+$ $[C]\{\dot{u}\}=0$, so the system inertia and damping effects aren't considered, only the stiffness which can provide quicker simulations and good approaches but, when the problem under study has loads that vary in value through time, these simulations could lack on the representation the full scale of the impact of the loads as studied by Liu, et. all [9] or for systems where there are many bodies in contact, this effects could also lead to inaccuracies as studied by Siswanto, et. all [10]. Furthermore, considering the temperature analysis as object of study, as in the work made by Wang, et. all [11], the transient simulation is the proper approach since in injection mold surfaces in contact with the molten plastic exhibit a high temperature variation as also presented on the work made by Babenko, et. all [12].

For this work was chosen a plastic part that although having simple geometry presents geometric factors that lead to stress concentrations in the tool. The tool will be analyzed on a coupled analysis but using quasi-static and transient algorithms to understand how they differ and how they can be used for the tool design although without considering any thermal load effects.

\section{Numerical study}

On this chapter will be presented the model under study and all the considerations made for this work. The numerical model will be studied using quasi-static and transient analysis using data obtained by previous simulations made in Moldflow. The use of Moldflow simulations is just to create the necessary data to export into ANSYS using macros designed to read the files generated by Moldflow and converting them, so they could be read. For such purpose a program was coded with Visual Basic to create the needed files using the algorithm presented in Figure 1.

As previously stated, only the pressure loads will be considered from the obtained results by the quasi-static and transient numerical simulations, being expected to understand how they affect the expected stresses, deformations and fatigue failure. For both simulations the first step will be equal, i.e., on the first step will be applied all boundary conditions, being those the bolt pretensions and clamping force. Subsequently, for quasi-static simulations, the pressure load it will be applied through 13 more steps accordingly to the time-steps obtained from Moldflow, for the transient simulation it is intended to study the stresses taking under account the duration and intensity of the pressure load. 


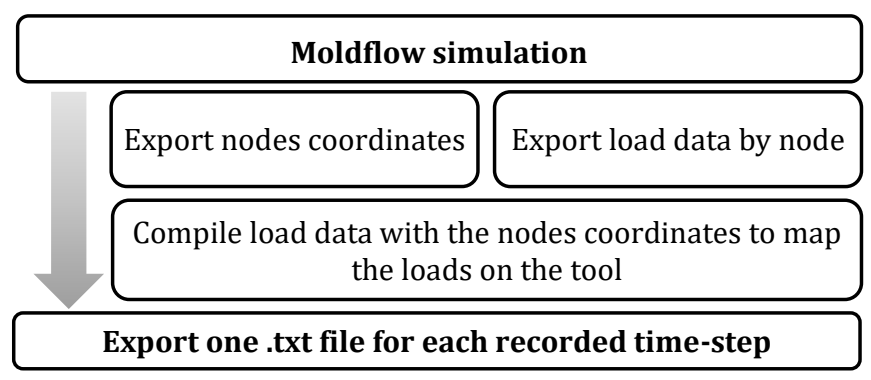

Figure 1. Algorithm used to create the loads map for ANSYS.

\subsection{Injection mold and materials}

To conduct this study a specially designed tool was used with all details to incorporate the problems which could appear in the production of injection molds, as is shown in Figure 2.

As for the injection mold materials it will be considered that this tool was made with 2 different steel grades: the core and cavity side is made from UDDEHOLM IMPAX SUPREME steel, which is a common tool steel used in injection molds, as for the rest of the components such as plates, ejectors and the sliders were considered as common structural steel.

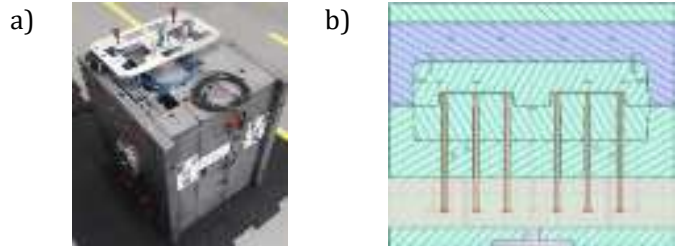

Figure 2. Injection tool under study a) photo of the tool, b) cross-section of the tool.

In Table 1 are presented the mechanical properties for the steel grades used on the numerical simulations. On this model the bolted connections have been simplified to a beam element and also these elements are considered as rigid and they are only applied on the core and cavity to reduce its degrees of freedom (DOF) and it will be considered that they will have similar properties to the UDDEHOLM IMPAX SUPREME.

Table 1. Steel mechanical properties

\begin{tabular}{cccccc}
\hline Steel & Density & $\begin{array}{c}\text { Young } \\
\text { Modulus } \\
{[\mathrm{E}]}\end{array}$ & $\begin{array}{c}\text { Yield } \\
\text { stress } \\
{\left[\mathrm{S}_{\mathrm{y}}\right]}\end{array}$ & $\begin{array}{c}\text { Ultimate } \\
\text { stress } \\
{\left[\mathrm{S}_{\mathrm{ut}}\right]}\end{array}$ & $\begin{array}{c}\text { Poisson } \\
\text { coefficient } \\
{[\mu]}\end{array}$ \\
\hline $\begin{array}{c}\text { UDDEHOLM } \\
\text { IMPAX }\end{array}$ & $\begin{array}{c}7.8 \\
\mathrm{~kg} / \mathrm{m}^{3}\end{array}$ & $205 \mathrm{GPa}$ & $\begin{array}{c}900 \\
\mathrm{MPa}\end{array}$ & $\begin{array}{c}1020 \\
\mathrm{MPa}\end{array}$ & 0.31 \\
$\begin{array}{c}\text { SUPREME } \\
\text { Structural } \\
\text { steel }\end{array}$ & $\begin{array}{c}7.85 \\
\mathrm{~kg} / \mathrm{m}^{3}\end{array}$ & $200 \mathrm{GPa}$ & $\begin{array}{c}250 \\
\mathrm{MPa}\end{array}$ & $\begin{array}{c}460 \\
\mathrm{MPa}\end{array}$ & 0.3 \\
\hline
\end{tabular}

For the fatigue curves it was considered for the structural steel the curves included on ANSYS database, as for the UDDEHOLM IMPAX SUPREME was considered the following theoretical assumptions:

- At 1000 cycles the stress value is $0.9 \mathrm{Sut}_{\mathrm{ut}}$

- At $10^{7}$ cycles the fatigue stress value $\left[\mathrm{S}_{\mathrm{f}}\right]$ is 0.35 Sut.

The use of $35 \%$ of the ultimate stress comes from theoretical research which states that for martensitic steels this is a conservative value [13].

\subsection{Numerical model}

To conduct this study several conditions were taken into account, such as the symmetry condition since this tool is symmetrical by its central plane and with it, it's possible to reduce the computation time. Also, it's considered that the injection machine plates are undeformable so they won't be considered on this simulation like the extraction plates of the injection mold, where all DOF are looked for the ejectors and slider at their bottom.

The bolted connections will not be considered, except for the connections on the core and cavity since these are the regions subjected to the higher stresses and more susceptible to displacements. Therefore, beam elements were placed to represent the bolts, which are considered as rigid and were placed to represent the bolts where the pretention will be applied and with it, the freedom restriction caused by the bolted connection will be considered.

As for the interactions between all the other surfaces, the following constraints have been considered according to their behavior during the injection process:

- For the surfaces which could slide between each other but, can't separate between each other was considered a contact that only allows sliding but no separation.

- For the parting line, i.e., the surfaces that separate the core side and cavity side was considered a contact which allows sliding and separation.

- For the extractor and sliders was considered also a contact that allows sliding and separation since there are parts which at the beginning aren't in contact but during the injection, this status could change.

- For the other surfaces is considered that they are bonded to the surface they are touching, and it's not allowed any displacement between each other

a)

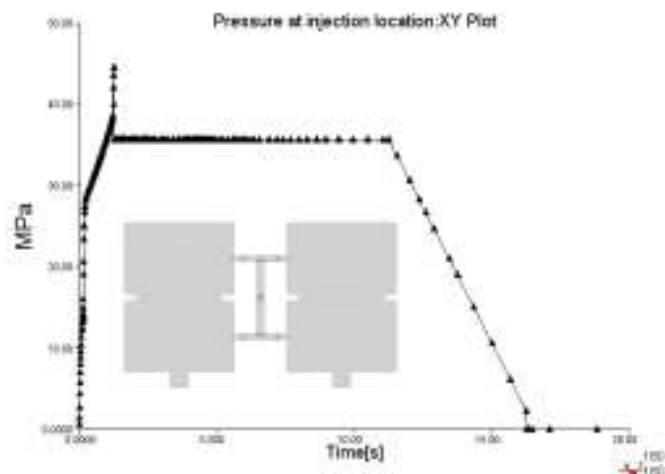

b)

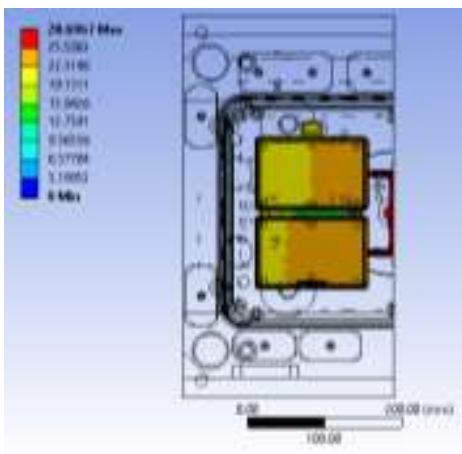

Figure 3. Pressure values a) at the hot runner entrance through the injection wet cycle and b) pressure distribution on the cavity at 1.81 seconds after the beginning of the injection.

For the pressure loads it was used data obtained from Moldflow, also the injection machine clamp force was obtained by those numerical simulations. But, as mentioned before only one half of the tool will be considered since there is a symmetry condition, so the clamping force obtained from Moldflow will be divided by two.

The beginning of the injection up to the end have a duration of the 17.5 seconds as can be observed in Figure 3- a) which will be considered on the simulations as previously stated. 


\section{Results presentation and discussion}

To analyze the results, it will be considered the differences on the von-Mises stresses, deformation of critical regions and the fatigue safety coefficient. For the fatigue safety coefficient, the Goodman criteria will be used which takes under account the equation (2), which will be used to analyze the differences from the obtained results. This evaluation will be one of the most important factors of comparison due to the variation of loads with time which could be very high and it's expected that these variations have a high impact on this value.

$$
\frac{\sigma_{a}}{\sigma_{e}}+\frac{\sigma_{m}}{\sigma_{y}}=1
$$

The first analysis will be of the von-Mises stresses from what will be observed how the stresses are distributed through the tool at the symmetry plane, as presented in Figure 4. It is possible to observe that the distribution is similar through all the simulations at the instant of highest pressure distribution through the tool, where the highest variation is at the regions where the bolted connections are applied which causes locally higher stresses. This is caused by the connection modeling and simplification made by the use of beam elements. From Figure 4 is also possible to observe for the transient numerical simulation that the von-Mises stress values are higher but they are present at a smaller region. a)
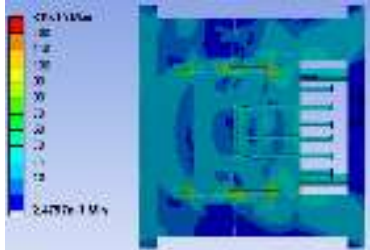

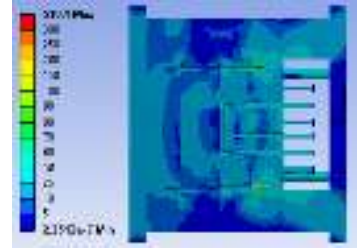

Figure 4. von-Mises stress distribution at the symmetry plane and at the time of highest pressure on the cavity a) quasi-static simulation, b) transient simulation.

To have a better perspective of the differences through all time-steps two regions where the stresses are higher on the core and the cavity were studied in detail. These are shown in Figure 5. a)

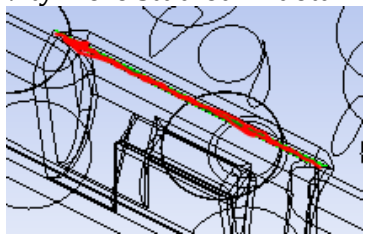

b)

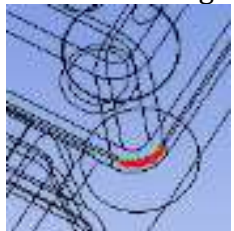

Figure 5. Stress probes locations: a) face at the cavity, b) blend at the core.

As it is possible to observe in Figure 6 the von-Mises stress values are similar from the instants where the first step is applied up to the highest pressure values. When the maximum pressure is applied to the cavity it is possible to check that there is a small discrepancy between the obtained values but, on the transient numerical simulation, the values are always smaller during the injection process. At the packing phase while the pressure keeps higher inside the tool, by the unloading phase the values aren't so similar, where the quasi-static simulation for almost of all the unloading phase is over-estimating the stresses values which will have an impact on the fatigue life calculations.

The parts deformations are an important result for this industry, since there are plastic parts defects caused by the displacement of components during the injection process and this is a major quality problem and the detection of this problem during the design is imperative.

On the results presented for the deformation, it won't be analyzed the relative displacement between parts, here is intended to understand how the results differ between different simulation

approaches, and for this it will be analyzed the regions presented in Figure 7.

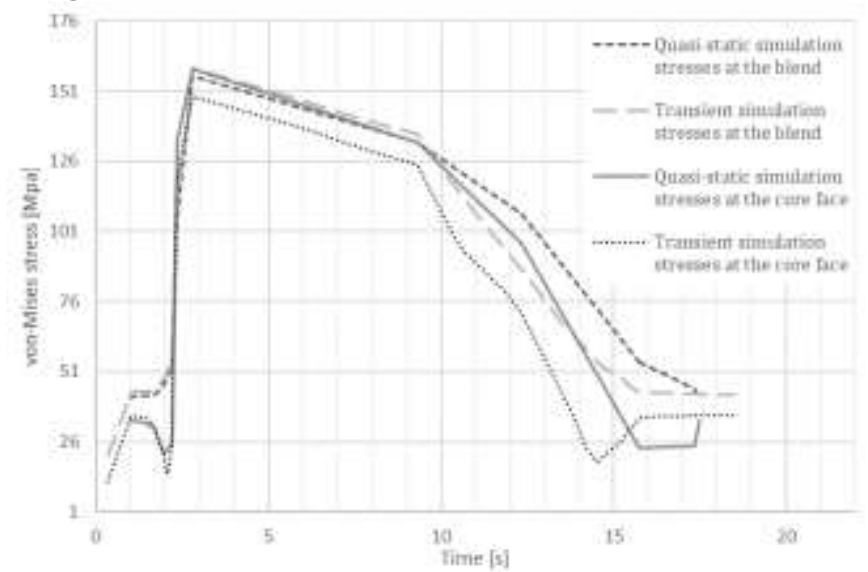

Figure 6. von-Mises stresses at a cavity blend and core face.

a)

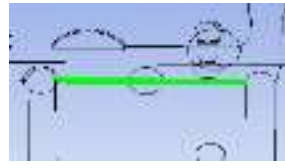

b)

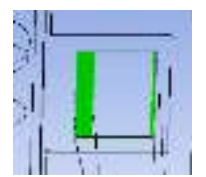

Figure 7. Deformation probes placed at a) an edge of the symmetry plane at the region where the pressures are higher and $b$ ) at a surface of a slider.

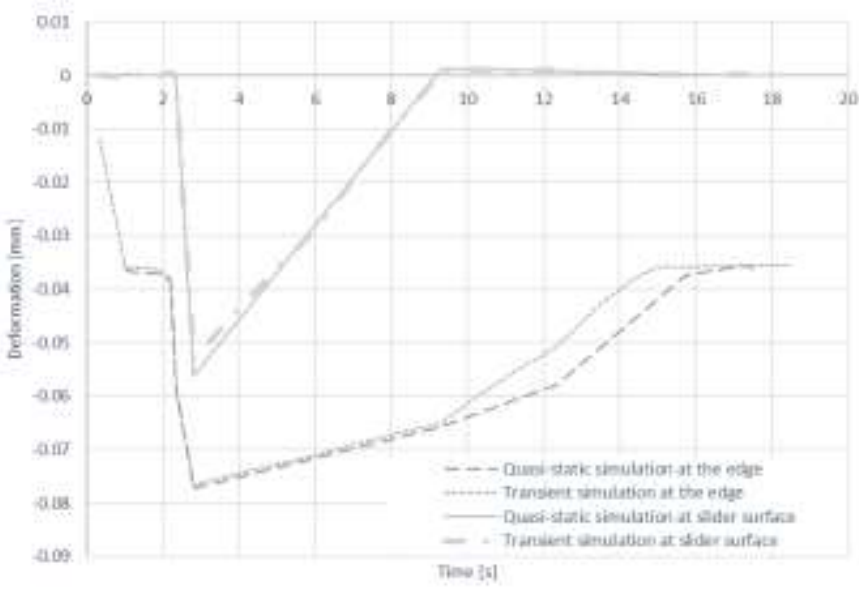

Figure 8. Maximum deformation at an edge of the symmetry plane at the region where the pressures are higher and at a surface of a slider.

In view of the results presented in Figure 8 the analyzed edge presents similar results for both simulations up to the instant of maximum pressure and, like was seen on the stresses results, the differences start to appear at the unloading phase but, for this simulation the plastic part isn't considered so isn't expected to have a precise result because at this stage the plastic part will have enough consistency to create some resistance to the steel elastic return. For the slider surface where the pressures aren't very high during the injection process and is one of the last regions to fill is possible to observe a difference between the transient simulation and the quasi-static one at the peak of pressure. For this part the differences look insignificant but it's a difference of around $4 \%$ at the peak of pressure which could be the difference between an aesthetical defect or not, and it could lead to an overestimation that could result on unnecessary extra design work. Therefore, the influence of the duration of the load shows how important is the use of transient simulations for these studies.

To analyze the fatigue safety coefficient for $1 \times 10^{9}$ cycles, it will be presented the results for the core since this is the region where 
the fatigue problems will be more evident due to the geometry which is very propitious for fatigue failure.

As stated during the stresses analysis, the increase of the stress values for the quasi-static simulation during the unloading phase shows a negative influence on the fatigue safety coefficient results, so as expected the values are lower but, for the regions where the loads are applied and at the most critical regions, the values are similar for this tool.

a)

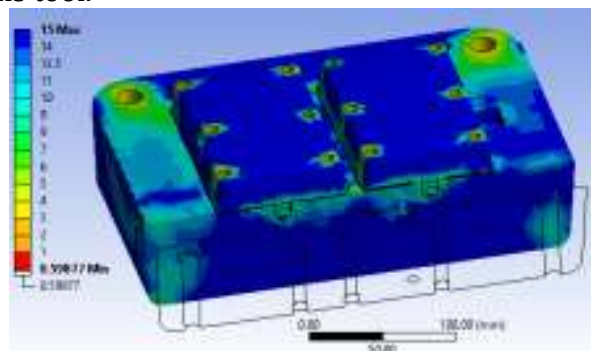

b)

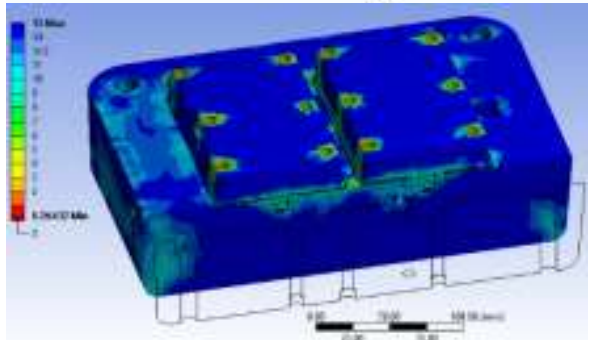

Figure 9. Fatigue safety coefficient calculated by ANSYS at the core for a) quasi-static simulation, b) transient simulation.

It is reasonable to conclude that for similar tools to the one studied, a quasi-static simulation considering all the loading timesteps could be used with care to obtain the fatigue safety coefficient but, it is not guaranteed that this approach is valid for tools where the loads present high variations through time along with their engraving region. However, the quasi-static simulation has a much lower computation time since it took 2159 seconds contrasting with the 15031 seconds for the transient simulation so, the transient simulation could lead to more accurate results but also is more time-consuming. Taking under account the results obtained is safe to conclude that the transient numerical analysis for fatigue calculations is more accurate and, for more complex tools, could present a more realistic approach since the influence of the load duration is taken into consideration. One should consider that in the injection tools localized load peaks could be present in systems where are present hot runners with many nozzles and with valve gates opening in sequence. But, for a quicker analysis, the quasi-static analysis could present an idea of the fatigue safety coefficient values and if extra design work is needed this could be a good solution to reduce the tool design time.

\section{Conclusions}

From the analysis made from the simulations it is possible to conclude that they can be used depending on the results which the designer is interested in: if the designer wants to have a better idea of stress variation during the injection process the quasi-static simulation could be a good approach due to its lower computation time. But the lower computation time comes with a cost for the accuracy of the results, the relative displacement between steel parts and the fatigue calculations. The relative displacement between parts if disregarded the duration of the load could lead to an overestimation of stresses and with it, the appearance of higher relative displacement values which will mislead the tool designer into making modifications that aren't needed. As for the fatigue design the same problem could be observed since the quasi-static simulations present higher loads when compared with the transient simulation at the unloading stage and consequentially there is a reduction of the safety coefficient.

For a future research is proposed to study a quasi-static simulation considering also the thermal loads and checking if this is a feasible approach to study the tool strength even knowing it could lead to an over-estimation because, if it could present values not too distant from the transient numerical simulations for a preliminary study it could be a good approach due to its lower computational time.

In conclusion, this work shows how to treat the data form Moldflow so it can be imported on ANSYS, also the execution of quasi-static and transient numerical simulations showed how they differ in results especially at the unloading stage, where, the quasistatic approach could induce designers to overestimate the stresses present in the tool. But, also the comparison of the simulations showed that they can both be used depending on the purpose and stage of the tool design.

\section{Acknowledgments}

The authors acknowledge the support provided by Grupo Simoldes, which contributed with their internal knowledge for the mold design and allowed the use of Moldflow. The funding support from project METRICS Ref. 2019 - UID/EMS/04077/2019 is acknowledged.

\section{References}

[1] I. Ferreira, J. A. Cabral, P. Saraiva, and M. C. Oliveira, "A multidisciplinary framework to support the design of injection mold tools," Struct. Multidiscip. Optim., vol. 49, no. 3, pp. 501-521, 2014.

[2] C. P. Chen, M. T. Chuang, Y. H. Hsiao, Y. K. Yang, and C. H. Tsai, "Simulation and experimental study in determining injection molding process parameters for thin-shell plastic parts via design of experiments analysis," Expert Syst. Appl., vol. 36, no. 7, pp. 10752-10759, 2009.

[3] M. S. Rusdi et al., "Numerical Investigation on the Effect of Pressure and Temperature on the Melt Filling During Injection Molding Process," Arab. J. Sci. Eng., vol. 41, no. 5, pp. 1907-1919, May 2016.

[4] Y. C. Lam, G. A. Britton, and Y.-M. Deng "A computer-aided system for an optimal moulding conditions design using a simulation-based approach," Int. J. Adv. Manuf. Technol., vol. 22, no. 7-8, pp. 574-586, Nov. 2003.

[5] H. Qiao, "A systematic computer-aided approach to cooling system optimal design in plastic injection molding," Int. J. Mech. Sci., vol. 48, no. 4 pp. 430-439, Apr. 2006

[6] R. Spina, "Injection moulding of automotive components: comparison between hot runner systems for a case study," J. Mater. Process. Technol., vol. 155-156, pp. 1497-1504, Nov. 2004.

[7] A. Bakharev and D. Astbury, "Simulation of ejection of moldings using combination of mold filling and thermo-mechanical analyses," in The 11th International Conference on Numerical Methods in Industrial Forming Processes, 2013, pp. 555-560.

[8] S. H. Tang, Y. M. Kong, S. M. Sapuan, R. Samin, and S. Sulaiman, "Design and thermal analysis of plastic injection mould," J. Mater. Process. Technol., vol. 171, no. 2, pp. 259-267, Jan. 2006.

[9] J. X. Liu, · S C Deng, and · N G Liang, "Comparison of the quasi-static method and the dynamic method for simulating fracture processes in concrete," vol. 41, pp. 647-660, 2008.

[10] W. A. Siswanto, M. Nagentrau, A. L. M. Tobi, and M. N. Tamin, "Prediction of plastic deformation under contact condition by quasi-static and dynamic simulations using explicit finite element analysis,$+ " J$. Mech. Sci. Technol., vol. 30, no. 11, pp. 5093-5101, 2016.

[11] G. Wang, G. Zhao, Y. Guan, and L. Huiping, "Three-dimensional thermal response and thermo-mechanical fatigue analysis for a large LCD TV frame mould in steam-assisted rapid heat cycle moulding," Fatigue Fract Eng. Mater. Struct., vol. 34, pp. 108-122, 2011.

[12] M. Babenko, J. Sweeney, P. Petkov, F. Lacan, S. Bigot, and B. Whiteside, "Evaluation of heat transfer at the cavity-polymer interface in microinjection moulding based on experimental and simulation study," Appl. Therm. Eng., vol. 130, pp. 865-876, Feb. 2018.

[13] J. E. Shigley, C. R. Mischke, R. G. Budynas, J. B. Aguiar, and J. M. Aguiar Projeto de engenharia mecânica. Bookman, 2005.

[14] R. I. Stephens and H. O. Fuchs, Metal fatigue in engineering. Wiley, 2001.

[15] A. F. Grandt, Fundamentals of structural integrity: damage tolerant design and nondestructive evaluation. J. Wiley, 2003. 
Figures

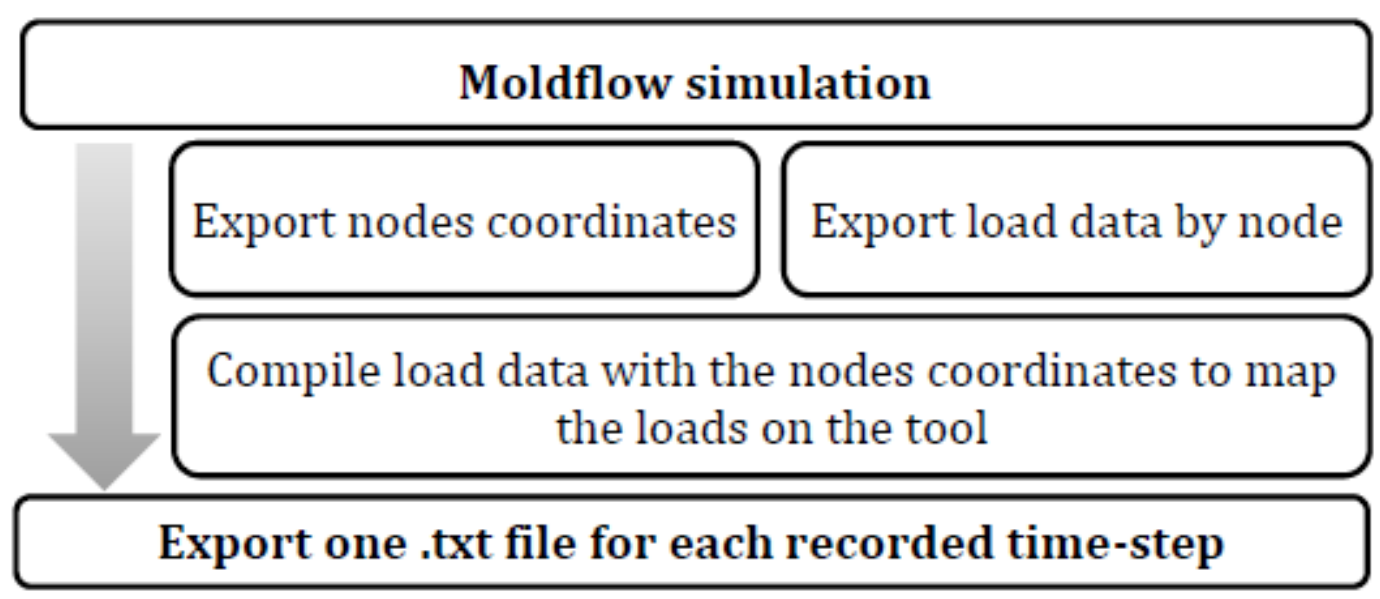

Figure 1

Algorithm used to create the loads map for ANSYS.

a)

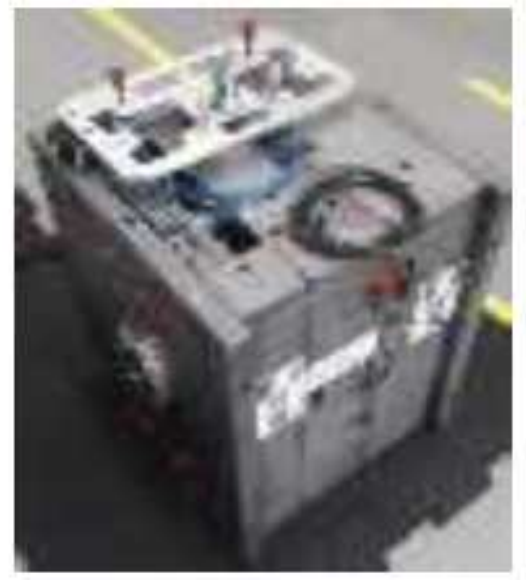

b)

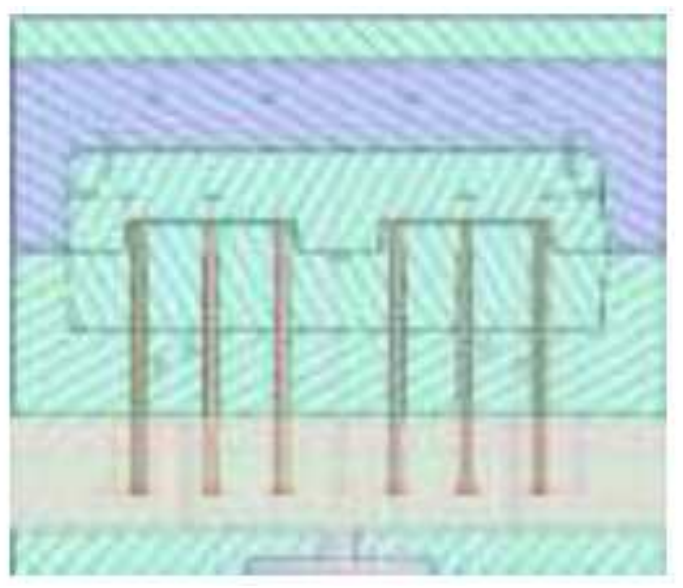

Figure 2

Injection tool under study a) photo of the tool, b) cross-section of the tool. 
a)

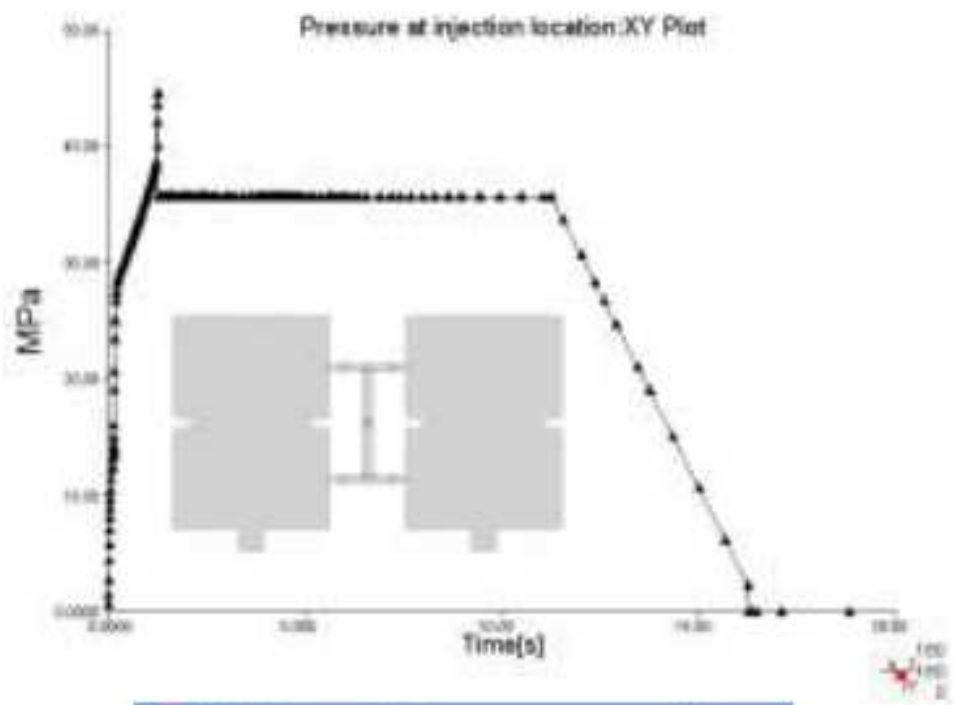

b)

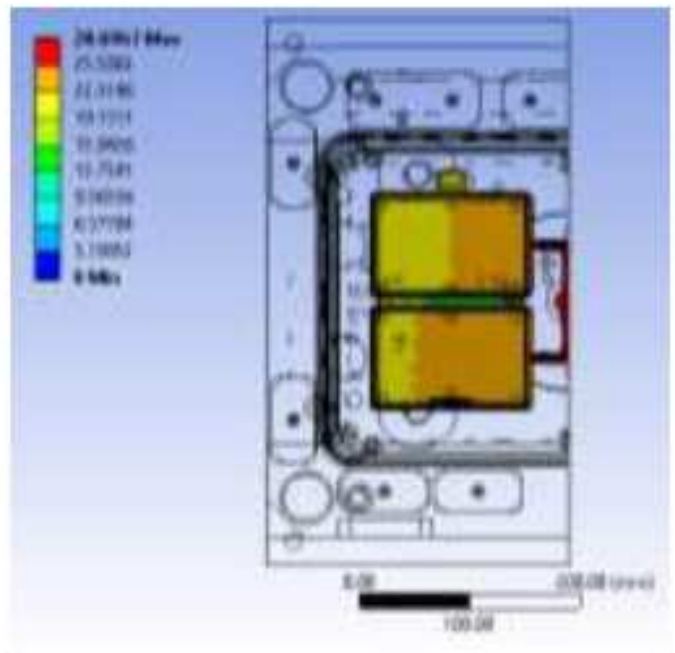

\section{Figure 3}

Pressure values a) at the hot runner entrance through the injection wet cycle and b) pressure distribution on the cavity at 1.81 seconds after the beginning of the injection.

a)
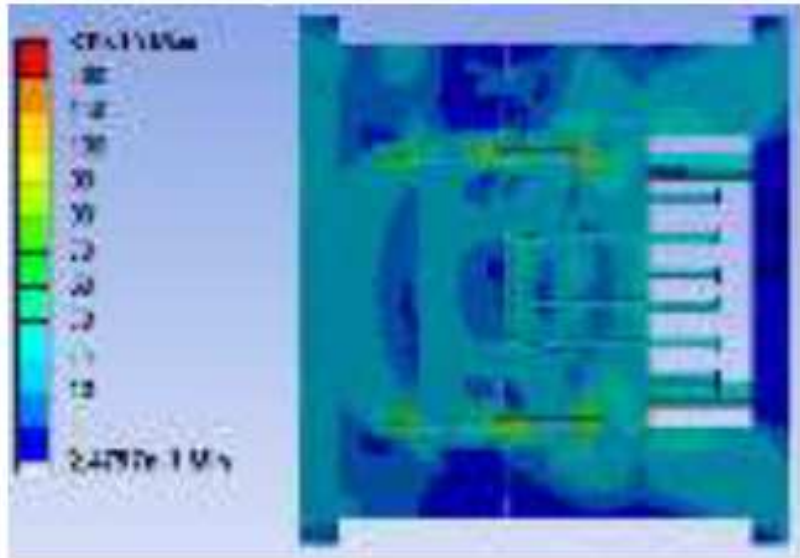

b)

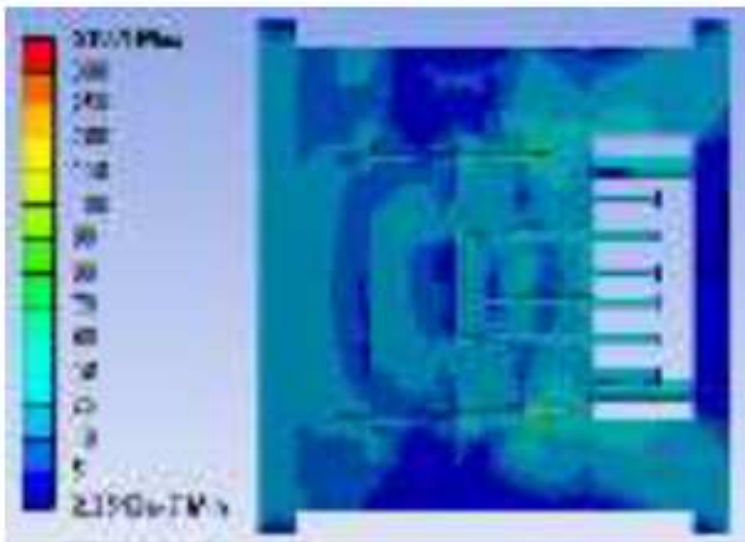

Figure 4 
von-Mises stress distribution at the symmetry plane and at the time of highest pressure on the cavity a) quasi-static simulation, b) transient simulation.

a)

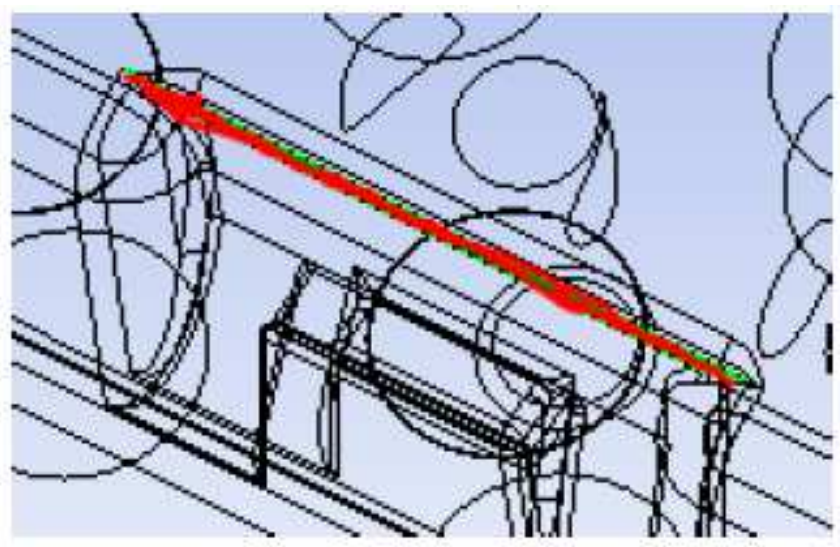

b)

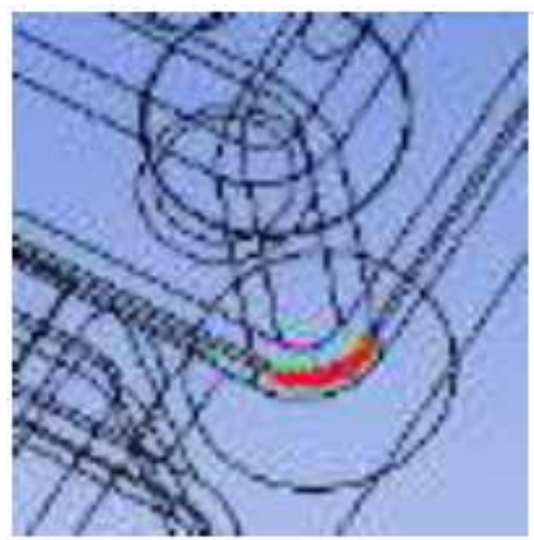

\section{Figure 5}

Stress probes locations: a) face at the cavity, b) blend at the core.

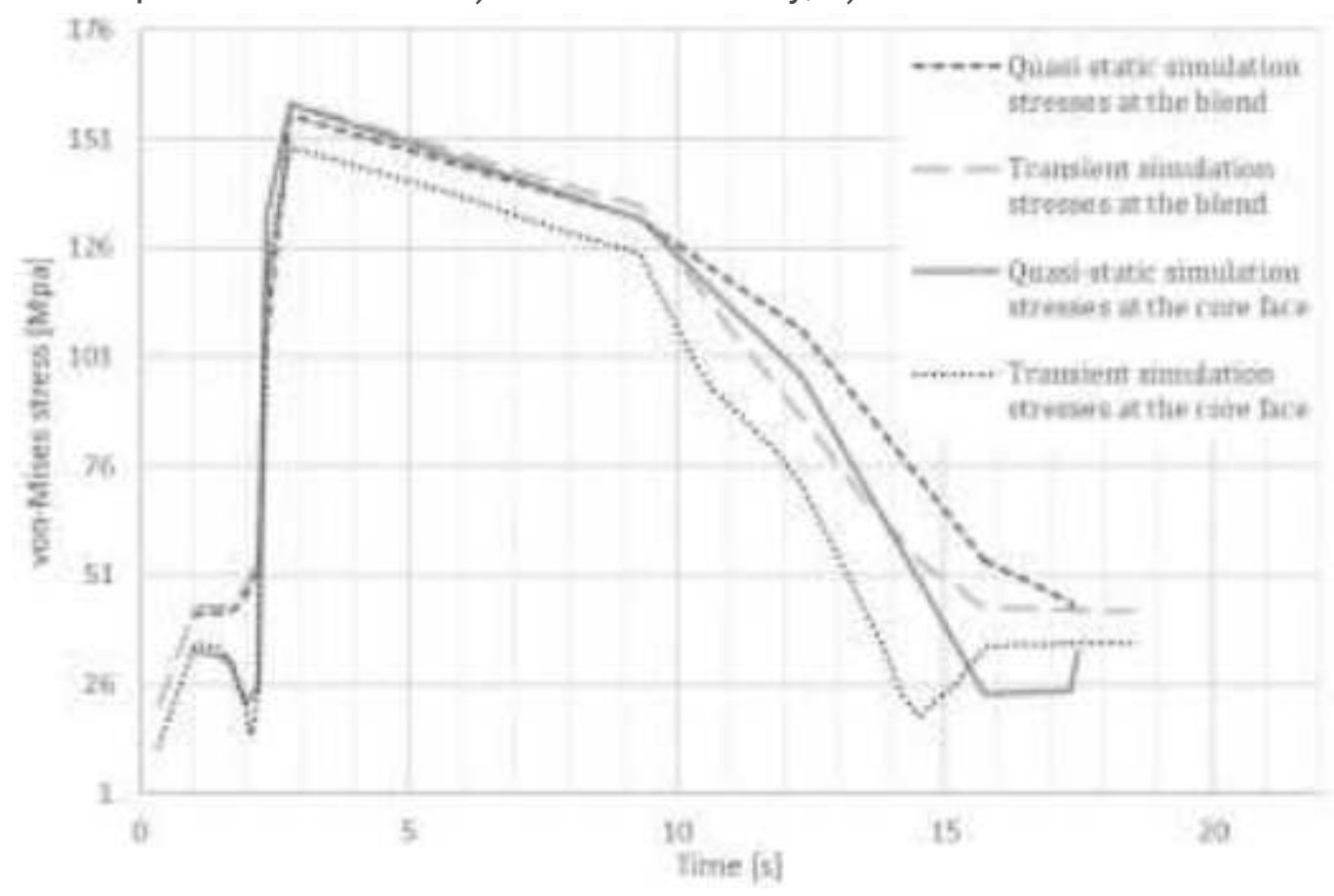

Figure 6

von-Mises stresses at a cavity blend and core face. 
a)

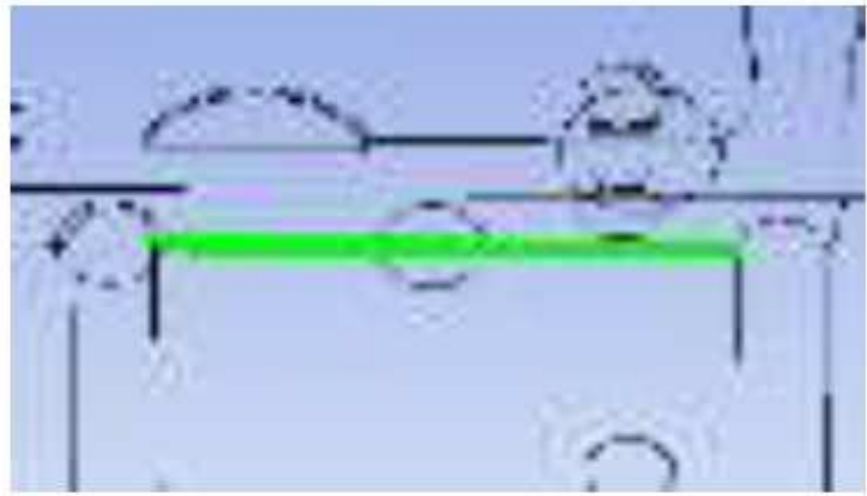

b)

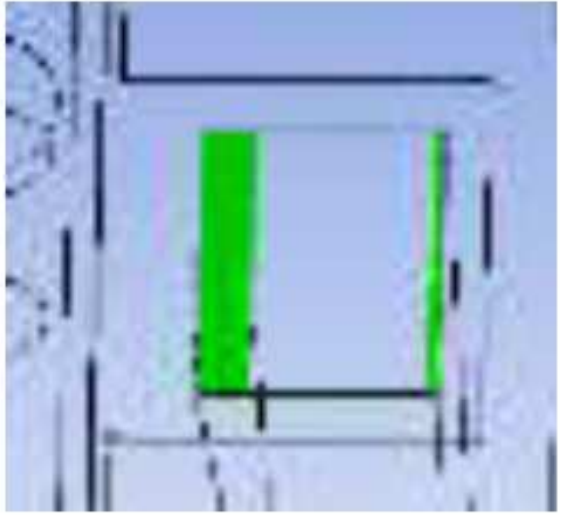

Figure 7

Deformation probes placed at a) an edge of the symmetry plane at the region where the pressures are higher and b) at a surface of a slider.

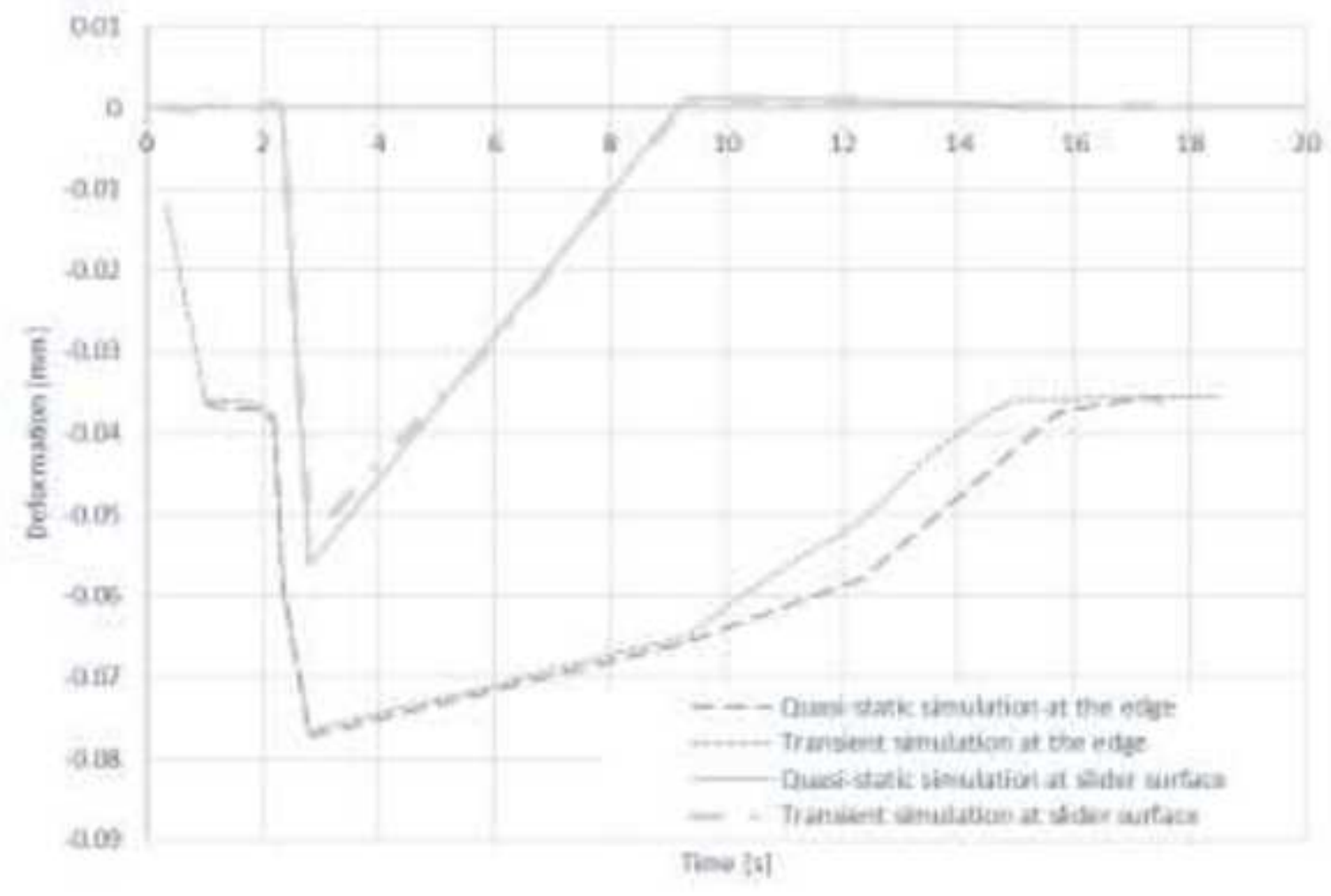

\section{Figure 8}

Maximum deformation at an edge of the symmetry plane at the region where the pressures are higher and at a surface of a slider. 
a)

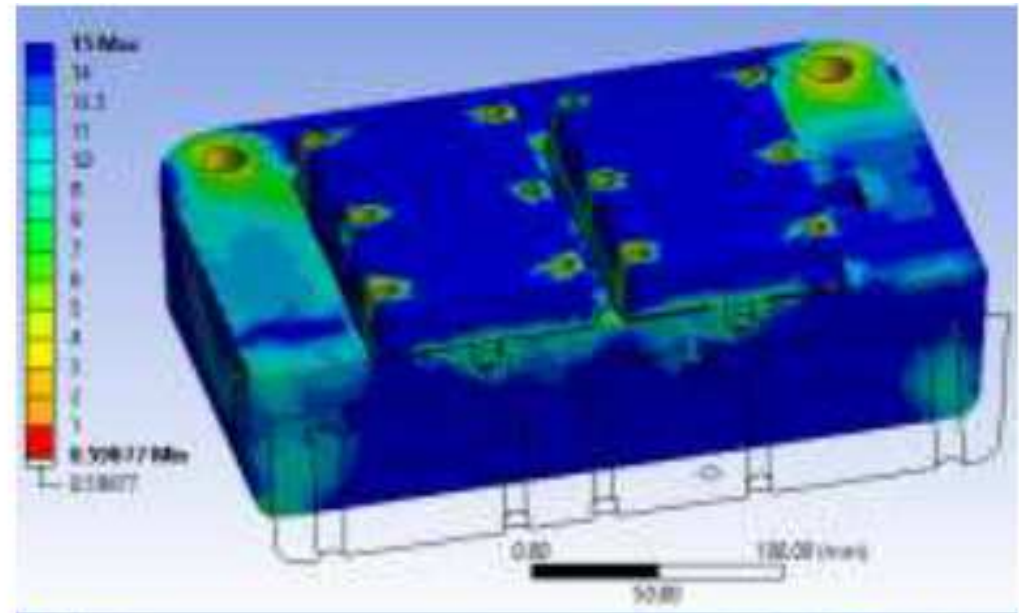

b)

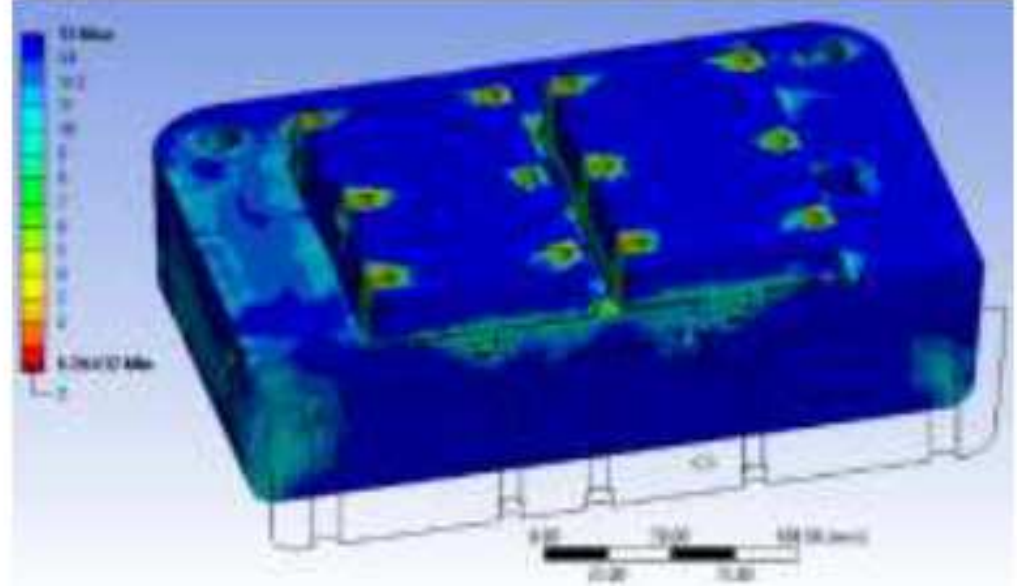

Figure 9

Fatigue safety coefficient calculated by ANSYS at the core for a) quasi-static simulation, b) transient simulation. 